\section{Lipid Contents and Classes in Gill of Masu Salmon Oncorhynchus masou during the Parr-Smolt Transformation}

\author{
Toshio Takeuchi,*1 Julius Sampekalo,*1 \\ Tetsuichi Nomura, ${ }^{* 2}$ and Takeshi Watanabe*1
}

(Received Jamuary 8, 1990)

In general, the lipid contents of salmonid fish, such as masu salmon Oncorhynchus masou, Atlantic salmon Salmo salar, the steelhead Salmo gairdneri, are changed by the parr-smolt transformation. The lipid contents in the body and muscle, especially the proportion of triglycerides (TG) in lipids, are reduced during the smolting period. ${ }^{1-B)}, * 3$ However there are still few reports on the changes of lipid profile which occur during the parr-smolt transformation.

On the other hand, it has been well known that the gill plays very important role in osmoregulation and respiration. ${ }^{3)}$

Recently, we have found that the total lipids (TL), especially $\mathrm{TG}$ in the gills decreased after adaptation to salt water for $24 \mathrm{~h} .{ }^{3}$ ) Bell et al. reported that gill epithelium may be sensitive indicator for essential fatty acid deficiencies in turbot. ${ }^{8}$. These findings suggest that the gill lipid in salmon may play some important role during the smolting period in addition to the functions mentioned above. Thus, this study attempted to find out variations of the lipid contents and lipid classes in the gill, and to compare the gill lipids with the body lipids in masu salmon during smoltification.

Masu salmon were collected fourteen times from the Hokkaido Salmon Hatchery, Chitose river, and Shiribetsu river from December to June in 1986, 1987 and 1988. In each sampling, 22-46 fish were caught to analyse lipid contents and lipid classes in the gill and body. The total lengths and body weights were 100.2 $143.2 \mathrm{~mm}$ and $10.5-24.5 \mathrm{~g}$, respectively. They were dissected to remove the contents of the stomach and intestines for whole body analysis, and the gills were also separated from the samples. Filter papers were used to remove blood from the gill. Both the gills and whole body samples were pooled for analyses. Details of the analytical conditions of lipid extraction and lipid classes were reported previously.?

TL and polar lipid (PL) contents in the gill and whole body are shown in Fig. 1. Both TL contents of the gill and body were reduced gradually from December to June. In particular the decrease was marked for the TL contents of the gill which decreased from $8 \%$ to $3 \%$. This result indicated that the gill lipids were affected more sensitively than the body during the parr-smolt transformation. On the other hand, the PL content in the gill and whole body were maintained at almost the same value at a level of $1 \%$ during this period. TG and phosphatidyl choline were main com-

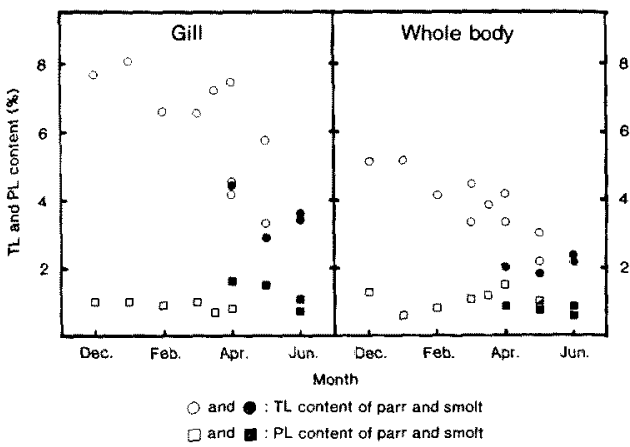

Fig. 1. Total lipid (TL) and polar lipid (PL) contents in the gill and whole body of Masu salmon Oncorhynchus masou during the parr-smolt transformation.

ponents in lipid classes of both the gill and whole body. On the other hand, minor components such as cholesterol esters, free fatty acids, free sterols, diglycerides, monoglycerides, phosphatidic acids, phosphatidyl ethanolamine (includes phosphatidyl inositol), sphinogomyerine, and lysophoshatidyl choline were also observed in both the gill and body lipids. Sheridan et.al. demonstrated that TG in the steelhead showed a clearer reduction than any lipid classes during the smolting period from January to April.4) Almost the same phenomenon that TG in the gills decreased markedly from December to June was also observed in our experiment with masu salmon. This result suggested that the changes of gill lipids were associated with the parr-smolt transformation, and gill lipids may have an important role during the smolting period in salmon. Details of lipid classes and fatty acid compositions in the gills and the effect of dietary lipids on the gill lipids in masu salmon during smoltification are under investigation. These results will be presented shortly.

\section{References}

1) T. Ota and M. Yamada: Nippon Suisan Gakkaishi, 40, 699-706 (1974).

2) A. Foda: Tech. Res. Ser. Dev, Branch Mar. Reg. Env. Can., No. MAR/T-72-2, 1-12 (1974).

3) I. C. Folmar and W. W. Dickhoff: Aquaculture, 21, 1-37 (1980).

4) M. A. Sheridan, W. V. Allen, and T. H. Kerstter: J. Fish Biol., 23, 125-134 (1983).

5) T. Nomura: Scientific Rep. Hokkaido Salmon Hatchery, 38, 34-41 (1984).

6) H. Ogata and S. Konno: Nippon Suisan Gakkaishi, 52, 313-318 (1986).

7) T. Takeuchi, S.-J. Kang, and T. Watanabe: Nippon Suisan Gakkaishi, 55, 1395-1405 (1989).

8) M. V. Bell, R. J. Henderson, B. J. S. Pirie, and J. R. Sargent: J. Fish Biol, 26, 181-191 (1985).

* Department of Aquatic Biosciences, Tokyo University of Fisheries, Konan, Minato, Tokyo 108, Japan (竹内传郎, J. Sampekalo, 渡辺武: 東京水産大学瓷源青成学科).

*2 Hokkaido Salmon Hatchery, Nakanoshima, Toyohira, Sapporo 062, Japan (野村哲一：北海道己汀 • す尔化場〉。

* T. Takeuchi, R. G. Ackman, and S. P. Lall: Unpublished data. 